\title{
Task-oriented Conversations: The Implications of Drama for Second Language Acquisition
}

\author{
Mohammad Khatib \\ Allameh Tabataba'i University, Tehran, Iran \\ Email: mkhatib27@yahoo.com \\ Somayyeh Sabah \\ Islamic Azad University, Science and Research Branch, Tehran, Iran \\ Email: somayyehsabah@yahoo.com
}

\begin{abstract}
Recently, there has been a growing interest in the utilization of conversations and dialogues in language pedagogy. The role of conversational task types in developing the $L 2$ oral proficiency in the process of Second Language Acquisition (SLA) has also received a great amount of attention. The present paper attempts at mulling over the current perspectives towards the role of dialogue and interaction in classroom environments with a stupendous emphasis on the implications of drama as a task-oriented conversation for SLA.
\end{abstract}

Index Terms - input, interaction, task-oriented conversation, drama, and second language acquisition

\section{INTRODUCTION}

As Saville-Troike (2005) puts it, the role of input comprehension is of primary significance in the domain of the Second Language Acquisition (SLA) research and theory. Language input to the learner is deemed to be absolutely necessary for either first language (L1) or second language (L2) learning to take place; however, the nature of its role is in dispute. Accordingly, Sanz (2005) argues that the emergent concern with the significance of the role of interaction with the social milieu has spawned a bulky agenda of studies rooted in the process of Second Language Acquisition (SLA) in recent years. All knowledge, particularly but not exclusively the linguistic knowledge, is regarded as the outcome of the learners' interaction with their social context, and the acquisition process is accordingly identified in terms of both social and cognitive factors.

\section{A. Input Hypothesis}

Krashen's (1982, p. 21) Input Hypothesis makes the claim that that in order for a second language (L2) acquisition to proceed, a necessary but not sufficient condition recommends the acquirers progress from the stage $i$ to the stage $i+1$ through getting exposed to and understanding comprehensible input that encloses certain structures "a little beyond" their current level of competence, where understanding means focusing on the meaning and not the form of the message.

Krashen's (1982) answer to the apparent paradox regarding understanding language structures that one has not yet acquired lies behind the rationale that the acquirers make use of more than their linguistic competence to help them understand. They can also utilize the clues in the context, their knowledge of the world, and their extra-linguistic information on the way to help them understand the language directed at them.

\section{B. Output Hypothesis}

Swain's (1985, p. 249, cited in, Gass \& Selinker, 2008, pp. 326-7) Comprehensible Output Hypothesis refers to the need for a learner to be "pushed toward the delivery of a message that is not only conveyed, but that is conveyed precisely, coherently, and appropriately." That is to say, as Park (2002) puts it, apart from comprehensible input, comprehensible output is also an indispensable condition for the L2 acquisition, and that learners are obliged, and, hence, make their output more comprehensible if communicative demands are put on them. This perspective is said to contrast penetratingly with Krashen's Input Hypothesis, wherein the role of production or output is minimized.

\section{Interaction Hypothesis}

In general, Long's (1983, cited in, Gibson, 2004) Interaction Hypothesis posits that interaction in L2 learning gives rise to SLA opportunities through what he terms the interactional modification. Now generally known as the negotiated interaction or Negotiation for/of Meaning (NFM), Long's (1996) newly-defined Interaction Hypothesis characterizes the negotiated interaction for L2 learners in terms of the process via which, in an attempt en route for communication, learners and competent speakers offer and construe signals of their own and their interlocutor's perceived comprehension, thus provoking adjustments to the linguistic form, conversational structure, message content, or all three, until a satisfactory level of understanding is established. 


\section{Vygotsky on Interaction: Zone of Proximal Development}

To put it in plain words, Vygotsky's Sociocultural Theory (SCT) regards interaction as the bedrock of the process of language acquisition. To explain the relation between the interpersonal and the intrapersonal plane, Vygotsky (1978, p. 86) develops the concept of the Zone of Proximal Development (ZPD), which he defines as "the distance between the actual developmental level as determined by independent problem solving and the level of potential development as determined through problem solving under adult guidance or in collaboration with more capable peers."

Accordingly, Johnson (2004) posits that Vygotsky distinguishes between two crucial levels of development, i.e., actual and potential. The former represents children's ability to perform mental activities without help from a more capable peer. This independence indicates that the functions associated with the independently performed activities have been stabilized; no intervention from another person is necessary. The latter level, the potential level of development, indicates that certain mental functions have not been stabilized; therefore, some intervention, namely assistance from a more capable peer or tutor is required. The difference between these two levels can be mathematically presented; that is to say, the potential level minus the actual level equals the Zone of Proximal Development (ZPD).

In an effort to explicate ZPD, Kumaravadivelu (2003) argues that two critical factors need to be emphasized; that is, the active participation by learners in meaningful interaction and the appropriate mediational assistance from competent speakers. From his perspective, Vygotsky's ZPD is an interactional construct in its own right.

To put it in plain words, Poehner (2008) muses that scaffolding is originally proposed as a way of actualizing learners' ZPDs; however, there has been an ongoing debate in the research literature over the extent to which assisting learners as they complete tasks is synonymous with mediating their development.

As discussed by Chapelle (1998), the SLA research directed at examining how learning activities can best be constructed to produce optimal input, output, and interaction has pointed out the importance of particular task features. Chapelle (1998) believes that the most useful perspective towards input, output, and interaction appears to be that of Pica, Kanagy, and Falodun (1993, cited in, Chapelle, 1998). Chapelle (1998) muses that based on a review of research on L2 communication tasks, Pica, Kanagy, and Falodun identify two task features that play a role in prompting valuable interactions in L2 tasks. They categorize these features under two variables, namely the interactional activity and the communication goal that are expected to influence the learners' language proficiency in significant ways and indicate the importance of extralinguistic task characteristics in creating positive conditions for at least apprehension, comprehension, intake, and output. They argue for an expanded model of SLA which includes relevant task characteristics.

According to Dobinson (2001), the use of interaction in language classrooms in recent years has become the norm at least as far as the language teachers are concerned, with teachers interpreting the interaction as a kind of the verbal communication between either the teacher and the students or the students and the students during the lesson. A communicative lesson has become the yardstick for successful lessons and practitioners often feel uncomfortable if they have not found certain ways of making their lessons more interactive or communicative.

In discussing the pedagogical implications of Long's (1996) Interaction Hypothesis, Jordan (2004) holds that there is more evidence at this juncture of the theory progression, of how an originally well-formulated hypothesis is upgraded in the light of criticisms and developments in the field. From the perspective of Jordan, the commitment to classroombased research is evident, and there are obvious implications for second language teaching. Two of the important implications of Long's (1996) hypothesis are that a task-based approach to classroom teaching is the most efficient, and that tasks can be selected and manipulated so as to maximize the opportunities for learners to turn input into intake.

In sum, Jordan (2004) maintains that, undoubtedly, the Interaction Hypothesis has amounted to the emergent support for a Task-Based Language Teaching (TBLT) approach to the classroom-based teaching where opportunities for the negotiation for/of meaning in Long's (1996) sense, and for noticing in Schmidt's sense are created. However, Jordan avers that the hypothesis occupies a limited domain and leaves untouched most of the questions relating to the SLA process.

\section{CONVERSATIONAL SCAFFOLDING AND L2 ClASSROOM INTERACTION}

In view of foregoing debates, Ellis (1985, cited in, Kitao \& Kitao, 1999) conducts an analysis of various studies and theoretical treatments of the subject and arrives at the conclusion that both input and interaction influence second language acquisition. He lists eight characteristics of input and interaction, which seem to facilitate rapid acquisition, based on this analysis. They are as follows:

1. A high quantity of input directed at the learner;

2. The learner' perceived need to communicate in the L2;

3. Independent control of the propositional content by the learner, e.g., control over the topic choice;

4. Adherence to the here and now principle, at least initially;

5. The performance of a range of speech acts by both the native speaker/teacher and the learner, i.e., the learner needs the opportunity to listen to and to produce language used to perform different language functions;

6. Exposure to a high quantity of directives;

7. Exposure to a high quantity of extending utterances, e.g., requests for clarification and confirmation, paraphrases and expansions; and 
8. Opportunities for uninhibited practice, which may provide opportunities to try out using novel forms.

As discussed by Nunan (1991), the central research issue posed in this line of argument is related to the designation of the specific classroom task types and patterns of interaction that provide the learners with the greatest amount of comprehensible input. According to Nunan (1991), it has been argued that patterns of interaction in which learners are forced to make conversational adjustments promote acquisition. This view represents an indirect rather than direct relationship between environmental factors such as types of instruction and language acquisition. It also refers to research which, while questioning the comprehensible Input Hypothesis, supports the communicative tasks to which it has given rise.

As a matter of fact, Larsen-Freeman and Long (1991) argue that the modification of the interactional structure of conversation may serve as an appropriate candidate for a necessary but not sufficient condition for the process of acquisition to occur. The role it plays in the negotiation for meaning helps to make input comprehensible while still comprising unidentified linguistic elements, and, therefore, potential intake for acquisition.

According to Sze (1996), it is common practice for general-purpose second/foreign language programs to incorporate the teaching of speaking skills. Speaking is often broken down into sub-skills, one of which is the ability to take part in a conversation in the target language. To begin with, it seems appropriate to address the issue of what kind of talk qualifies as conversation. While monologues such as lectures, speeches, and TV news reports are obviously to be ruled out, talk involving more than one speaker does not necessarily constitute conversation. With respect to the classroom context, even though there may be a great deal of oral interaction between teacher and students during a lesson, few people would accept as true that the teacher is having a genuine conversation with the students.

From a second language perspective, Dufficy (2005) debates that more open forms of classroom communication only transpire when the teachers loosen the reins on the minds of the learners in their classrooms and support them to move into challenging novel cognitive domains through the utilization of dialogues and conversations for the duration of the classroom talk. When this takes place, the learners can learn not only the essential values of critical, independent thinking, but more profound values to do concerning others' viewpoints, have a tendency to put forward an unusual idea, trust in getting a fair hearing, and show a certain amount of flexibility as they come to perceive uncertainty and mistakes in thinking as the very building blocks of thought itself.

\section{A. On Conversation}

In defining conversation, Button, Oatley, and Draper (1989, cited in, Micarelli \& Boylan, 1997) begin by proclaiming principles with which one could hardly agree more, including (1) even when engaged in smalltalk, people speak with a purpose, as philosophers of language like Austin (1962, cited in, Micarelli \& Boylan, 1997) and Searle (1969, cited in, Micarelli \& Boylan, 1997) have long pointed out; and (2) goals, like other aspects of meaning, are negotiated during a conversational exchange.

In line with the foregoing argument, Micarelli and Boylan (1997) present the debate that the basic scenario of a conversation if the term conversation implies, as it should, involves the negotiation of discourse goals through tradeoffs that contrasts with the scenario of what language teachers call an open dialogue, involving a set exercise with constrained responses that generally express a pre-determined thematic flow, cleverly arranged to give the student the illusion of conversing. Micarelli and Boylan (1997) aver that open dialogue exercises, which abound in printed form in the better foreign language textbooks, are said to be a positive step forward, if compared to the old-fashioned fill in the blank grammar exercises.

\section{B. Scaffolding and Situated Cognition}

Firth and Wagner (1997, cited in, Larsen-Freeman, 2007) call for a more socially and contextually situated view of SLA research that has generated a great deal of discussion and debate in the domain of SLA. Larsen-Freeman (2007) discusses that given the individualistic, cognitive origin of the SLA field, such controversy is entirely understandable. With different ontologies and epistemologies, the two views, individual/cognitive and social/contextual, have had little impact on each other. In this sense, Larsen-Freeman (2007) argues for the theoretical pluralism that has prevailed in recent times and proposes to think of the possibility that requires a reframing of the current understanding.

Accordingly, Wagner and Gardner (2004) criticize the mainstream SLA on the grounds that it has been first and foremost a conglomerate of theories and methods; however, the main glue that keeps the diverse approaches in SLA theory together is the concept of language as primarily form, and the understanding of acquisition as individual cognition, i.e., an accomplishment of the (single) human mind. That is to say, theories in SLA model the learner as an input-output processing unit in a sender-receiver model of communication. Accordingly, they call for the incorporation of conversations in the second languaeg in the classroom enviornments.

As discussed by Mondada and Doehler (2004), both Sociocultural Theory (SCT) and Conversation Analysis (CA) congregate in maintaining the fundamental role of contextually embedded communicative processes in the accomplishment of human actions and identities as well as of social facts. In bringing these two lines of thought together, Mondada and Doehler (2004) are determined to stress that learning activities are both negotiated and accomplished in local contexts and transmitted and elaborated across historical contexts.

Mondada and Doehler (2004) present the argument that learning a language, in this sense, essentially means learning how to cope with contextualized, interactionally oriented discourse activities. That is to say, language learning 
engrosses much more than a simple account of an expert-novice relationship and much more than scaffolded sequences of the negotiation. More specifically, Mondada and Doehler debate that language learning has its roots in the learners' participation in organizing talk-in-interaction, structuring participation frameworks, configuring discourse tasks, interactionally defining identities, and becoming competent members of the community or communities wherein they partake, whether as students, immigrants, professionals, or indeed any other locally relevant identities. Such participation gives rise to cognitive practices, forms of attention, and conjoined orientations that are embedded, publicly exhibited, and made recognizable in actual actions, and are socially mediated and collectively monitored through interaction. In this sense, Mondada and Doehler debate that cognition can be said to be socially situated in a twofold sense, in the sociocultural definition of the situation as well as in the local contingencies of everyday actions.

\section{Second Language Conversations}

Technically, Wagner and Gardner (2004) identify second language onversations as involving speakers whose first language is not the language of the talk that have become widespread in the globalized world. Such conversations may take place in a variety of situations in which people go about their daily routines in work and private life while interacting in a second language. The approach adopted by Wagner and Gardner (2004) assumes language to be embedded in the wider practices of verbal and non-verbal talk. It also assumes that talk is a collaborative construction created by all participants, at all times, so that neither language production nor reception, neither speaker nor listener are privileged in any analysis.

In the light of the foregoing, Wagner and Gardner (2004) debate that language serves as one vehicle for action, which is in turn an essentail element for the generation of the social world. As such, they place a primary focus on how participants manage to achieve successful outcomes in their interactions, rather than on the deficits they may have as non-native speakers. From their pespective, second language conversations should be conceived of in terms of normal conversations. This is not surprising when one takes into account that these second langauge speakers are not engaged in task completion exercises in the classroom or laboratory, but are engaged in everyday meaning creation and activities which mean something to them.

\section{Task-oriented Conversations}

Technically, Seedhouse (2004) adopts a critical perspective towards TBLT/SLA approaches and presents the argument that a number of problems have emanated from TBLT/SLA's current focus on the task-as-workplan. Seedhouse argues for the shift of attention to the task-in-process in the classroom inspired by the work of certain authors (e.g., Ellis 2001, cited in, Seedhouse, 2004). In this respect, he sketches certain characteristics of the taskoriented interaction as a variety of interaction and proposes to balance the rosy TBLT/SLA theoretical claims with the empirical evidence of certain less-than-rosy practical drawbacks.

From Seedhouse's (2004) point of view, the task-oriented interaction is identified in terms of a particular narrow and restricted variety of communication wherein the whole organization of the interaction is geared toward establishing a tight and exclusive focus on the accomplishment of the task. There are a multitude of different varieties of interaction in the world outside the L2 classroom, where there is certainly a lot more to communication than performing tasks. In the task-oriented context the pedagogical focus on the communicative and practical outcome of the activity and the turn taking system is reflexively related to the task-in-process and oriented to the successful accomplishment of the task. That is to say, the task-oriented interaction is by and large not relevant to the talk of topic or meaning; rather, the learners' focus is on the task.

According to Seedhouse (2004), there are various different sub-varieties of communication that can occur in the L2 classroom. Despite the seemingly impressive theoretical arguments put forward to promote TBL, it remains to be proven that the task-oriented interaction is more effective than other sub-varieties of the classroom interaction.

To shed more light on the matter, Taboada (2004) holds that the taxonomy of speech genres would contain the scheduling genre under a more general type of task-oriented conversations. In these, the participants come together to complete a task. That is, they enter into a process of collaboration. In Rich and Sidner's (1997, 117, cited in, Taboada, $2004,34)$ term, it is "a process in which two or more participants coordinate their actions toward achieving shared goals."

Taboada (2004) brings to mind the imperative point that the defining characteristics of task-oriented dialogues are not collaboration and cooperation in and out of themselves. Rather, the most defining characteristic is grounded on the fact the goal is a practical one, which the speakers are committed to achieve. Other conversations have also goals; however, these might be of a less practical nature such as establishing rapport or maintaining social links. That is to say, conversational tasks are conducive to gain a communicative goal of a further practical nature.

Taboada (2004) muses that as the task-oriented conversation proceeds, the speakers are said to construct more common knowledge from the exchanged information. New information that is conveyed by one speaker is usually acknowledged as received by the other speaker, thus allowing them to enter the common ground. Grounding is conceived to be a collaborative process, namely the listener sends certain signals representing understanding, and the speaker cares for those signals. In case such a context of situation is not present she or he usually rephrases, repeats, or performs other comprehension checks. In view of this line of argument, the task-oriented conversation is considered as a collaborative process in which process is made only when the two participants share the same beliefs. 


\section{DRAMA AS A TASK-ORIENTED CONVERSATION}

To put it simply, Mehta, Dow, Mateas, and MacIntyre (2007) argue that an interactive drama is, in a sense, a pure hedonic experience, immersing the player in a dramatic social interaction without providing, as most games do, a clear player goal; that is to say, the player invents goals for herself/himself as the interaction with the characters unfolds. Interactive drama presents one of the most challenging applications of autonomous characters, requiring characters to simultaneously engage in moment-by-moment personality-rich physical behavior, exhibit conversational competencies, and participate in the dynamically developing story architecture. Successful future research in believable agents requires deploying such agents in completed dramas, evaluating the effectiveness of the agents in creating a compelling player experience and utilizing the results of the evaluation to guide future research.

As said by Mehta et al., (2007), conversation-centered interactive dramas, which put the player in rich social contexts of situation wherein the prime interaction is accomplished through conversations, proffer interesting evaluation challenges. In the first place, methodologies drawn upon to evaluate the task-based conversation systems are inappropriate, as they employ metrics based on efficiency and task accomplishment; players in interactive dramas do not merely complete tasks; rather, they are engaged in a dramatic experience. Second, as most interactive dramas to date have been small prototypes rather than fully-realized experiences, it has been difficult to develop evaluation methodologies. Finally, in an interactive drama, the success of a conversational turn hinges on whether and how the player is able to incorporate the conversational turn into his or her growing understanding of both the characters and the narrative situation. This inherently qualitative process resists simple approaches to quantifying the conversational turn success. It is worth mentioning that this dependence on player interpretation implies that system level technical failures such as misunderstood player input and/or the selection of incorrect responses, though helpful to know, do not necessarily cause a player-perceived conversational breakdown.

For Mehta et al., (2007), the design of the story itself, including the authoring of the conversational content, is instrumental in determining whether the player has a pleasant experience, and how and whether technical breakdowns impact this experience. Consequently, the effectiveness of technical and design techniques employed in the interactive drama needs to be related back to the player's perceptions during the interaction. Ideally, one wants a player-centric evaluation methodology that starts with the player's experience and analyzes how the technical and design approaches used in the system impact the experience, thus providing insights for creating more engaging player experiences in future systems.

\section{A. Process Drama: A Tool for Classroom Conversations}

From Wagner's (1990, cited in, Liu, 2002) point of view, the pragmatic use of language learned through Process Drama over a variety of activities, such as scenarios, improvisations, and meaning-negotiations practiced in the classroom prepares students for the better communication in the real life. Furthermore, through Process Drama, students from diverse linguistic and cultural backgrounds can build social skills and become more sensitive listeners and more apt and mature conversationalists. They also grow in their capacity to send and receive increasingly complex and mature verbal messages effectively, independently, creatively, and symbolically.

According to Evert (2008), through the use of drama as a teaching strategy the facilitator is said to implement certain activities, which would become a link between the learning outcomes, assessment standards, and the critical and developmental outcomes. It is through this strategy that one is likely to adopt a holistic approach rather than viewing the learning areas as non-related.

Evert (2008) believes that in order to achieve an integrated approach to teaching and learning, there needs to be a shared knowledge or certain guidelines for the facilitator. These rules are in addition to many others that are common knowledge to most facilitators. These guidelines act as a structure or compass that the facilitator can use to determine whether the learning activities will be beneficial to the learners and successful as a whole.

According to Byron (1986, p. 22, cited in, Evert, 2008, p. 14), the medium of drama and the drama as a teaching strategy as a whole has certain basic laws:

1. Drama explores human actions, attitudes, values, and relationships, through a shared fiction and by means of an agreement to pretend.

2. This fiction operates in the present tense, in now time, namely the participants including the class and teacher engage with the events of the drama as they are happening.

3. Drama is examined from a dual viewpoint, firstly from the viewpoint where participants become or represent the people in the drama and secondly from interactants' point of view, as people making and reflecting on the interaction, i.e., both as spectators and participants.

4. Drama is a teaching strategy wherein the primary medium of expression is the person. The learner's body and voice is the instrument. Practice and opportunity develop the control of this medium.

5. Dramas should occur in a safe environment. An established set of rules should determine the boundaries and ethos of the classroom. When the learners feel safety, they are more likely to express themselves in various ways.

\section{B. Types of Drama in SLA Classrooms}


According to Moody (2009), drama is a useful medium in the communicative language classroom where the focus is placed on the meaning of language rather than form. Activities come in various forms depending on purpose, curriculum, class size, or experience. Moody splits them roughly into two categories; work with text and work without text. Moody (2009) believes that the latter one in particular encourages learners to try to communicate using their own limited language resources. There is more freedom for students to create personal meaning from the activity. However, the advantage of working with a script is that it provides vocabulary and also helps students explore multiple viewpoints of the narrative.

\section{The Role of Role Plays in the SLA Context}

As Zafeiriadou (2009) puts it, drama in the L2 context can include dramatic play and improvisations, story enactment, imagination journeys, theatre games, etc. Because the emphasis in creative drama is process rather than product, teachers have the freedom to take as much time as needed with their classes.

According to Zafeiriadou (2009), during a fundamental technique of drama, role play participants empathize with a role either of a person or an object and experience new-fangled knowledge in three spatial dimensions, namely length, width, and height and three psychological dimensions, i.e., identification, internalization, and empathy. Additionally, three fundamental mental dimensions including representation, assimilation, and imagination; three social dimensions comprising of participating by taking on a role, interaction, and acceptance by others; and three personal dimensions identified as self-development, self-esteem, and self-actualization of role playing coalesce effectively to enable children to understand and to acquire the necessary skills to cope with the environment. All of these aspects are constructive in the process of language acquisition for the reason that they can make available a multidimensional base for stimulating and developing language.

\section{Arguments for the Use of Drama in SLA Classrooms}

For Zyoud (2010), drama is an engaging teaching strategy that props up cooperation, collaboration, self-control, goaloriented learning as well as emotional intelligence skills. Drama bridges the gap between course-book dialogues and the natural usage and can also help to fill in a similar gap between the classroom and real life situations by providing insights into how to handle tricky situations. Drama strengthens the bond between thought and expression in language, affords practice of supra-segmental and para-language, and proffers good listening practice. If drama is considered as a teaching method in the sense of being part of the eclectic approach to language teaching, then it can become a focal support in the acquisition of the communicative competence. Drama activities facilitate the type of language behavior that should lead to fluency, and if it is accepted that the learners want to learn a language in order to make their identities understood in the target language, then drama does indeed further this end.

From the perspective of Zyoud (2010), one of the greatest advantages to be gained from the utilization of drama is that students become more confident in their use of English by experiencing the language in operation. Drama in the English language classroom is ultimately indispensable because it provides the learners with the opportunity to exploit their own personalities. It brings into play students' natural abilities to imitate and express themselves, and if wellhandled should arouse interest and imagination. Drama encourages adaptability, fluency, and communicative competence. It puts language into context, and by giving learners experience of success in real-life situations it should arm them with confidence for tackling the world outside the classroom.

\section{E. Tips for Facilitating Interactions through Conversations}

To be precise, Gibson (2004) argues that EFL instructors teaching English conversation need to constantly remind themselves that their goal is to build up the conversation skills of their students. Large classroom settings are clearly not ideal for the teacher to facilitate such development. Nevertheless, it is important for teachers not to get discouraged by this. A full-fledged course design that allocates the students plenty of interaction in groups and pairs, homework activities that address the development of conversation skills, classroom activities and tests that are relevant to conversation development, and the discipline to be able keep to this course design week in and week out will bring about an English conversation course that lives up to its billing.

Technically, Gibson (2004) provides the EFL teachers with certain guidelines regarding the regulation of the conversational activities in the classroom settings, which are as follows:

1. During speaking activities the teachers are recommended be wary of the students who have memorized reading from notes. Legitimate questions concerning the message they are attempting to communicate should be asked. Probing for further information from the student is advisable, particularly if the teachers feel that the content has been memorized or is being read.

2. The teachers are advised to treat the conversation as an interaction with the student. If the instructors are not sure of the message that the student is trying to communicate, then they must negotiate the meaning with the student.

3. The teachers are required not to allow the students who visit their offices to take notes. The learners may refer to their notes before beginning the task; however, once the task has begun they are not permitted to draw on their notes. The teachers need to instruct the students to prepare well before engaging in the activity.

4. The instructors should encourage the students regardless of their communicative abilities. For example, the instructors can respond to all e-mails with a couple of lines to indicate that they are aware of the content of the message. 


\section{CONCLUSION}

In due course, the present paper has made an attempt directed at scrutinizing a specific sub-variety of the classroom communication, namely the task-oriented conversations or dialogues. It is debated that the task-oriented conversations are distinguished from other types of conversational exchanges given that they require the interactants to achieve a communicative goal of a practical nature, which, according to Taboada (2004), amounts to the establishment of a common ground or a shared frame of reference by encouraging the learners to investigate the language through the meaningful interaction in, to fall back on Vygotsky's (1986, p. 99) terminology, a "non-threatening environment." It has been also the aim to take account of the genre of the interactive Process Drama as a tool for the accomplishment of such task types in the SLA classroom.

\section{REFERENCES}

[1] Boyd, G. M. (2004). Conversation theory. In D. H. Jonassen (Ed.), Handbook of research for educational communications and technology (2nd ed. pp. 179-197). Mahwah, NJ: Lawrence Erlbaum Associates.

[2] Chapelle, C. (1998). Multimedia CALL: Lessons to be learned from research to instructed SLA. Language Learning and Technology, 2(1), 21-39. http://llt.msu.edu/vol2num1/article1 (accessed 25/10/2011)

[3] Dobinson, T. (2001). Do learners learn from classroom interaction and does the teacher have a role to play? Language Teaching Research, 5(3), 189-211.

[4] Dufficy, P. (2005). Becoming in classroom talk. Prospect, 20(1), 59-81.

[5] Evert, L. S. (2008). Drama as a tool for second language acquisition. Unpublished master's thesis, University of Johannesburg, Gauteng, South Africa. http://ujdigispace.uj.ac.za:8080/dspace/bitstream/10210/3484/1/Evert.pdf (accessed 25/10/2011)

[6] Gass, S. M., \& Selinker, L. (2008). Second language acquisition: An introductory course (3rd ed.). New York: Routledge.

[7] Gibson, G. (2004). Facilitating English conversation development in large classrooms. Internet TESL. Journal 10(9). http://iteslj.org/TechniquesGibson-Conversation.html (accessed 25/10/2011)

[8] Johnson, M. (2004). A philosophy of second language acquisition. New Haven: Yale University Press.

[9] Jordan, G. (2004). Theory construction in second language acquisition. Amsterdam: John Benjamins.

[10] [10] Kitao, S. K., \& Kitao, K. (1999). Using on-line chat in language teaching call and learning community. Proceedings of the Eighth Biennial CALL Conference, University of http://ilc2.doshisha.ac.jp/users/kkitao/library/article/exeter.doc (accessed 25/10/2011)

[11] Krashen, S. D. (1982). Principles and practices in second language acquisition. Oxford: Pergamon.

[12] Kumaravadivelu, B. (2003). Beyond methods: Macrostrategies for language teaching. New Heaven: Yale University Press.

[13] Larsen-Freeman, D. (2007). Reflecting on the cognitive-social debate in second language acquisition. The Modern Language Journal, 91, 773-787.

[14] Larsen-Freeman, D., \& Long, M. H. (1991). An introduction to second language acquisition research. London: Longman.

[15] Liu, J. (2002). Process drama in second- and foreign-language classrooms. In G. Bräuer (Ed.), Body and language: Intercultural learning through drama (pp. 51-70). Westport, CT: Ablex.

[16] Long, M. H. (1996). The role of the linguistic environment in second language acquisition. In W. C. Richie \& T.K. Bhatia (Eds.), Handbook of research on language acquisition (pp. 413-468). New York: Academic Press.

[17] Mehta, M., Dow, S., Mateas, M., \& MacIntyre, B. (2007). Evaluating a conversation-centered interactive drama. Paper presented at Proceedings of the Sixth International Joint Conference on Autonomous Agents and Multiagent Systems (AAMAS), Honolulu, Hawaii, USA. http://www.cc.gatech.edu/ mehtama1/publications/AAMAS07.pdf (accessed 25/10/2011)

[18] Micarelli, A., \& Boylan, P. (1997). Foreign language tutoring systems today: Old-fashioned teaching with newfangled gadets. Journal of the European Society for the Study of Cognitive Systems, 5(1), 37-56.

[19] Mondada, L., \& Doehler, S. P. (2004). Second langaueg acquisition as situated practice: Task accomplishment in the French second language classroom. The Modern Language Journal, 88(4), 501-518.

[20] Moody, M. (2009). "Make Your Own Drama" in the EFL Classroom. Journal of the School of Contemporary International Studies, 3(5), 379-391.

[21] Nunan, D. (1991). Communicative tasks and the language curriculum. TESOL Quarterly, 25(2), 279-295.

[22] Park, E. S. (2002). On three potential sources of comprehensible input for second langaueg acquisition. Teachers College, Columbia University Working Papers in Applied Linguistics. http://journal.tclibrary.org/index.php/tesol/article/view/22/25 (accessed 25/10/2011)

[23] Poehner, M. E. (2008). Dynamic assessment: A Vygotskian approach to understanding and promoting L2 development. Norwell: Springer Publishers.

[24] Sanz, C. (2005). Adult SLA: The interaction between external and internal factors. In C, Sanz (Ed.), Mind and context in adult second language acquisition: Methods, theory, and practice (pp. 3-20). Washington: Georgetown University Press.

[25] Saville-Troike, M. (2005). Introducing second language acquisition. Cambridge: Cambridge University Press.

[26] Seedhouse, P. (2004). The interactional architecture of the language classroom: A conversation analysis perspective. Malden: Blackwell.

[27] Sze, P. (1996). Teaching conversation in the second language classroom: Problems and prospects. Educational Journal, 23(2), 229-250.

[28] Taboada, M. T. (2004). Building coherence and cohesion: Task-oriented dialogue in English and Spanish. Amsterdam: John Benjamins.

[29] Vygotsky, L. (1978). Mind in society: The development of higher mental processes. Cambridge, MA: Harvard University Press.

[30] Vygotsky, L. (1986). Thought and language. Cambridge: The MIT Press.

[31] Wagner, J., \& Gardner, R. (2004). Introduction. In R. Gardner \& J. Wagner (Eds.), Second language conversations (pp. 1-17). London: Continuum. 
[32] Zafeiriadou, N. (2009). Drama in language teaching: A challenge for creative development. ISSUES, 23, 4-9.

[33] Zyoud, M. (2010). Using drama activities and techniques to foster teaching English as a foreign language: A theoretical perspective.http://www.qou.edu/english/conferences/firstNationalConference/pdfFiles/muntherZyoud.pdf (accessed 25/10/2011)

Mohammad Khatib is the professor at Allameh Tabataba'i University, Tehran, Iran and the professor of TEFL at Islamic Azad University, Science and Research Branch, Iran, Tehran. He has published numerous articles in the area of TEFL. Needless to say, he delivers Ph.D. courses, such as Learning Theories and Teaching English Literature.

Somayyeh Sabah is an instructor of TEFL at Islamic Azad University of Khorramabad. She did her M.A. at Shahid Chamran University, Ahvaz, Iran. Currently, she is a Ph.D. candidate of TEFL at Islamic Azad University, Science and Research Branch, Tehran, Iran. She is active in teaching speaking and reading courses. Her areas of interest are Second Language Acquisition, Discourse Analysis, Critical Pedagogy, and Literature in TESOL. 